\title{
Studying Aspects and Indices of Social Capital of Universities-A Case Study of Zahedan Islamic Azad University
}

\author{
Ali Reza Sargolzaie ${ }^{1}$ \\ ${ }^{1}$ Management department, Islamic Azad University, Zahedan Branch, Iran \\ Correspondence: Ali Reza Sargolzaie, Management department, Islamic Azad University, Zahedan Branch, Iran. \\ E-mail: hamed_dba@yahoo.com
}

Received: June 17, 2014

Accepted: August 16, 2014

Online Published: September 25, 2014

doi:10.5539/ijbm.v9n10p116

URL: http://dx.doi.org/10.5539/ijbm.v9n10p116

\begin{abstract}
The study addresses the dimensions and indicators of social capital to provide an appropriate model for social capital pathology in universities. The aim of the study is applicable, the data was collected by correlating - study method which was conducted in survey. The population includes 400 faculty members from Islamic university of Zahedan. The seven dimension of social capital such as identity, empowerment, cooperation and public benefit, trust, cooperative management, knowledge sharing and social net are measured in current and desired condition. The methods of collecting information are including: library study (books, journals, database, Internet...) questionnaire by using SPSS software the amount of trust coefficient is calculated with Alpha Cronbach and the statistical society of this research is professors of Islamic Azad University, Zahedan Branch. In order to study causative relationship between variables it was benefit from structural equations with multi variable analysis including: Confirmatory Factor Analysis, Classical Simultaneous Equation Models, Path Analysis, multi regression, variance analysis and other statistical methods. And the result of this study shows that there is significant relationship between them.
\end{abstract}

Keywords: social capital, trust, knowledge sharing, identity, empowerment, cooperation, net

\section{Introduction}

Today in addition to human and economic capital, the social capital is recognized as another effective variable in developing process. This concept refers to links and communication between members of a network as valuable resources that reveals economic reserve of cultural and social items and human capital; in which, finally leads to improving group communication between humans, organizations and humans, organizations with organizations and society. On the other hand, social capital is very effective for developing countries that intend to take step that are faced with several impediments including: ineffective administrative sector, low level of trust and poor partnership morale and may promote most of these impediments through benefiting from such capital.

Researches show that groups and societies benefiting from higher social capital generally have lower level of social damage; thus, persons, groups and societies benefit from this issue in order to obtain its suitable results. Being informed of social capital in organization is a very important issue.

Obtaining to development requires studying fundamental solutions and having different resources in under developed societies is regarded as basic and important grounds for development. Social capital in addition to economic capital and human capital have recently recognized as strong effective variable on development process (Alvani \& Shirvani, 2005). The concept of social capital is an inner field concept that is recently received attention by many human sciences branches. Many thinkers and theoreticians believe that social capital is a network of relationships and links based on inner personal and inner group trust and communication of persons, groups, organizations and social associations that by benefiting from correlation, social coherence and benefiting from support groups and potentials attempt to obtain the individual and group objectives (Abdollahi \& Mousavi, 2006). Thus, social capital is regarded as resource for many persons, groups and societies for obtain to the desired goals and responds to find answer for this question that why some societies reach to more positive results.

Benefiting from social capital consists of networks, norms and social trust that are components of today's life and enables societies to cooperate with other in order to obtain common goals. Increasing partnership of people 
at social associations plays effective role on increasing social capital and increasing social capital plays key role on developing society.

Today researchers and analyzers of macro-management systems believe that evolution series of moving toward industrial society to knowledge based society is due to quick growth of invisible assets and social activity toward visible resources. Therefore, obtaining this capital is classified as a form of capital of global bank and on this basis as Lekstor refers social activity plays key role on knowledge based economy and consists of a group of resources that lead to qualifications and abilities for increasing social activities, capacity of creating, sharing and management of knowledge production. On this basis, Vilanova \& Josa (2003) defines social capital as a managerial phenomenon that consists of following properties including: trust, norms, values, common behaviors, communication, cooperation, mutual commitment, mutual recognition and networks. Therefore, researchers believe that social capital is regarded as a managerial phenomenon with the aforesaid properties that leads to obtaining to mutual advantage; in which, organization is unable to operate without some of these properties.

Today the success of organizations is not only limited to accumulating capital and equipping to modern physical facilities, IT and communication; since, financial, physical and human capital regardless to social capital is ineffective. Although it's been many years that social organizations have received attention by management scientists, the importance of social relationship and social capital in organization is a new topic that has raised attention in recent decade and success of organizations and their effectiveness depends on improving social capital; so that optimum application of other capital in organization regardless to social capital is impossible. At the present time being informed of status of social capital and its relationship with each other is necessary for any social and cultural planning, specially when the discussion of social capital at 20 years development program of Iran and 5 years development program and important role of universities for reaching to first economic, scientific and technological status is focused. Thus, researcher attempts to study components, indices and advantages at level of universities, so that upon designing suitable models to describe the importance of each index at universities.

\section{Literature Review}

\subsection{Terminology of Social Capital}

Social capital as it is obvious from its title refers to link between 2 concepts of capital and society which is among new and complicated concepts of sociology that is applied in other scientific fields as well and therefore introducing its concept is very important. The term capital refers to accumulated wealth specially a type that is mainly applied for producing wealth (Webster dictionary). Capital is cash that is allocated to a person or institute that may be invested for obtaining income rather than its depreciation (French \& Sard, 1992). In addition, capital in its public meaning refers to set of assets, facilities and resources that are revealed within different forms and types.

\subsection{Sharing Knowledge}

Since knowledge was replaced for land, workforce and capital as elementary resource of competitive advantage, the ability of creating new knowledge, partnership at available knowledge and applying organizational knowledge for new opportunities became very important issue (Lesser, 2000); since, productivity is described as efficiency, quality and flexibility. The necessity of establishing knowledge based organization is transferring information and knowledge at macro-level and micro-level between persons and organizations and therefore it is focused on communication based on mutual trust. If an organization is able to increase effectiveness of communication among its employees, groups and organizational units, it may be more certain to increase effectiveness of communicating among people and consequently obtaining effective organizational management (Bhatt, 2001).

Ingram and Argoteh defined knowledge transfer as a process that influences on experience of others. They believe that sharing knowledge is revealed through changing knowledge and performance of its receiver units and such changes are regarded as criterion for transferring knowledge of organizations (Argoteh \& ngram, 2000). Brochner focuses on process of sending and facilitating knowledge transfer; in which, a person prepares knowledge and sends it to a potential receiver (Brochner, 2004).

Cordey-Hayes \& Gilbert describe the process of sharing knowledge as a tool for organizations to apply new technologies. They look to knowledge as ability of recognizing inner and outer information and applying it for commercial results and goals. Vito et al believe that knowledge transfer is strategic and in this way, organization is able to obtain competitive advantage. Knowledge transfer and share is vital factor for organization to quickly respond changes and innovation and become successful. In this study knowledge transfer and share in university 
as an organization is regarded as a process that through its application a specific activities are performed including: obtaining knowledge and information, distributing information, meaningful information, organizational memory and recovering knowledge and information (Vito et al., 1999).

\subsection{Enabling}

We live in age that is full of chaos and complexity and the world is faced with continuous changes more than ever i.e. the property of today's world is continuous changes and organizations in order to cope with such challenges should be aware of their vital role for learning, developing and survival. In fact, organization should attention to develop knowledge, skill and abilities of its employees (Nolan, 2002). This issue leaded to regarding effective, skilful and partnership human workforce as the most important, valuable capital and resource of an organization that plays key role on permanent development of a society. Enabling employees is among effective solutions for increasing productivity of employees and benefiting from individual and group capacity in the way of organizational objectives. Mr. Lee defined enabling as a means for increasing dialogue, critic idea and activity of small groups and refers that permitting small groups to move toward sharing experiences, ideas, observations and dialogue are the main components of enabling (Lee, 2001). Enabling is a continuous process; in which, persons of a society benefit from self-confidence and are enable to have correct assessment and recognition of themselves and be informed of their abilities for obtaining to their goals and through increasing their abilities may meet their objectives (Farokhi, 1997). Enabling means people should reach to a level of individual development that enables them to select based on their demands (Shaditalab, 2002). Fox believes that enabling employees is a process; in which, an enabling culture is developed and goals, objectives, decision making, result of influence and attempts is shared within total organization and in such culture, the resource and competition is supported for understanding required resources of increasing effectiveness of organization (Fox, 1999). Enabling has root in attitude and behavior of employees of an organization and deals with improving ability of organizational relationship and structure; since, enabling is not achieved through applying pressure to managers, rather enabling is a process that requires accepting culture of enabling and partnership of employees (Erstad, 1997).

\subsection{Network}

Structural aspect deals with properties of a social system and network of relationships as a general model. This term describes non-personal configuration and the link between people or units (Nahapit \& Goshal, 1998). By benefiting from concept of structural aspect of social capital, it is possible to refer to general pattern of communication between role players i.e. who as access to you and how you are accessible (Bert, 1992). Meanwhile, the most important property of this aspect is existence or non-existence of network links between role player of plans (scott, 1991; Wasserman, \& Foust, 1994). Network configuration (Kerakehard, 1989) or morphology(Ticky, Tushman \& Fomburn) is a pattern for link between contraction scales, connectivity and hierarchy and the term "flexible organization" mean some networks that are created for a specific goal and may also applied for other goals as well (Kolman, 1988).

\subsection{Cooperation}

The term cooperation simply means partnership and cooperative for performing common activities and plan, in other words, a teamwork that the entire members benefit from their potential abilities, scientific recommendations, innovations, modern ideas, decision making, planning, execution and utilization in order to obtain a common specific goal. The synonyms of this term are including: "collaboration, participation, coordination" that each of them refer to the concept of cooperation and teamwork. Now we compare and describe of the words separately

Collaboration: Working with a person or group of people for inventing or producing something (Oxford Advanced Learners Dictionary 2005). American Heritage Dictionary defines collaboration as teamwork by having common mind. This definition in Persian language is equivalent to cooperation

Cooperation: Means performing work with each other in order to obtain common goals (Oxford Advanced Learners Dictionary 2005). This term in Persian language is equivalent to the term "cooperative"

Participation: Means attending in an event or activity (Oxford Advanced Learners Dictionary 2005) Oxford English Dictionary (1989) defines this term as" participating, communicating or sharing resources about an action or a topic, this topic is equivalent to term "partnership".

Coordination: Means collecting a group of people for performing a similar task effectively (Oxford Advanced Learners Dictionary 2005). American Heritage Dictionary (2001) has defined this term as "working together by arrangement". This term is equivalent to term "Arrangement" in Persian language. Arrangement is one of the 
main duties and performances of management. Duties of each group and its members should be determined in advanced for obtaining to maximum efficiency for obtaining to goals. These duties may require relationship inner network that has priority with respect to time. Duties may be hierarchy, vertical or horizontal i.e. any action is correlated with its prior or later action (Hendricksen, 2002).

Mattessich \& Monsey (2002) about the following 3 terms as: "partnership" "arrangement" "cooperation)" states that there is no agreement about definition of cooperation; since, this term has many ambiguities and contradictions. In fact, cooperation is replaced with partnership and arrangement; nevertheless, thinkers regard difference about "partnership" "arrangement" "cooperation)". The most considerable property of partnership is unofficial relationship. Within partnership, the information is shared and offered to any organization upon necessity; therefore, there is no danger and as the resources are separated, they benefit from separated bonus as well. Arrangement is determined by more official relationships and understanding missions and depends on planning, labor and role division and it is necessary to create some canals for communication. Although power remains in single organizations, there is great danger for all coworkers and bonus is offered mutually Mattessich \& Monsey (2002).

Cooperation refers to long lasting and comprehensive relationships. Having cooperation terms completely separated organizations into new structure with full obligation toward common mission. The requirements of such comprehensive planning and communication means is that to be defined appropriately. The power determines structure of cooperation and whereas resource and respect each coworker is dealt with, the probability of danger is higher. The common resources are obtained and the resources are common as well Mattessich \& Monsey (2002).

\subsection{Research Background}

1) Research of Potnam in the year 1995 was among the first researches dealing with social capital. This was research at macro level in relation to social capital that deals with analyzing reducing of partnership of citizens at political affairs of U.S.A. Potnam benefit from 2 methods including: "time series" "sample temporary data" in order to analyze research information that many researchers originated from his research methodology (Fokoyama 1999). He also neglected qualitative aspects of social capital and level of correlation and inner group coherence of networks.

2) Fransis Fokoyama is among another famous researcher in the field of social capital. He studies the most important aspect of social capital at macro level in society of America. His studies deal with society of America since 1950's until 1990's coping with negative indices of social system including: divorce, separating family, crime, prostitution and etc. In fact, Fokoyama through studying social abnormalities and specifically misusing family attempts to justify reduction of social capital in western society. However, it is to be noted that absence of social abnormalities is due to having suitable social capital; nevertheless, social abnormalities is not necessarily due to reducing social capital or determining its share. Another criticism on research of Fokoyama is his limited attitude toward concept of social capital. He believes that social capital is synonym to trust and through studying level of trust attempts to study the topic of social capital.

3) HOGARTh \& Michaud studied social capital by focusing on its structural aspect among senior American and French managers. This is comparative study in order to determine contraction of organizational networks and assessing its additional relationship within network and results show there is more contraction for senior managers of American companies i.e. French managers have more preference to start communication with unknown and new networks and welcome from such communication.

4) carrierle ana \& Hary, y.van Buren in the year 1999 carried out research among American companies in relation to assessment of social capital aspects. They believe that organizational social capital has 2 aspects "trust" "correlation". The correlation deals with trust and ability of organizational members in society and working together for obtaining to common group goal. Upon regarding these 2 aspects, carrierle ana \& Hary, y.van Buren study the topic of organizational social capacity

5) Gamas 2007 in his research he analyzed the relationship of sharing knowledge among organizations and the relationship between shared knowledge and its communication, inner relationship of satisfaction of communication, communicational styles, offering and collecting knowledge. Results show that sharing knowledge is completely related to satisfaction of communication, offering knowledge and style of communication and collecting knowledge.

6) Totar man \& wul ff 2007 studied sharing information in an university through social capital attitude. They evaluated social capital and sharing knowledge through 3 variables (social identity, effective trust, partnership 
and personal relationship) and concluded that sharing information among sectors, continuous local networks and foreign network of faculty is performed effectively. Within this environment, the main requirement of social capital is available. The interviewees focus on sharing information and complained to current status i.e. lack of trust, competition for obtaining rank, not having obligation to workspace

7) Hi- Hony Park (2006) and Ston (2002) in their research studied the role of trust on knowledge creation in a virtual organization. They refer that the main condition for producing social capital is situation, motivation and ability and concluded that trust influences on knowledge creation through opportunity, motivation and ability of mixing knowledge at a virtual organization and factors including: unofficial network, norms, common values and mutual trust are effective on knowledge creation

8) Feizi 2006 carried out research for designing and describing model of social capital at Payam Noor University. This research deals with social capital mode of Nahapit and Goshal. Results of research show that communication and mutual trust has direct relationship with social capacity of university and outer variables and relationship element (organizational norms and feeling obligation) and concentrated network (structural element) influences on social capital through legal factor. Among 7 component variables the relationship for 4 variables of communication and mutual trust (directly) organizational norms and feeling obligated (indirectly) on social capital of university is proved. Factors including IT and communication influences on social capital through mutual trust

\subsection{Conceptual Research Model}

Through observing theoretical basics and research background, the conceptual model of this present is offered in Figure 1.

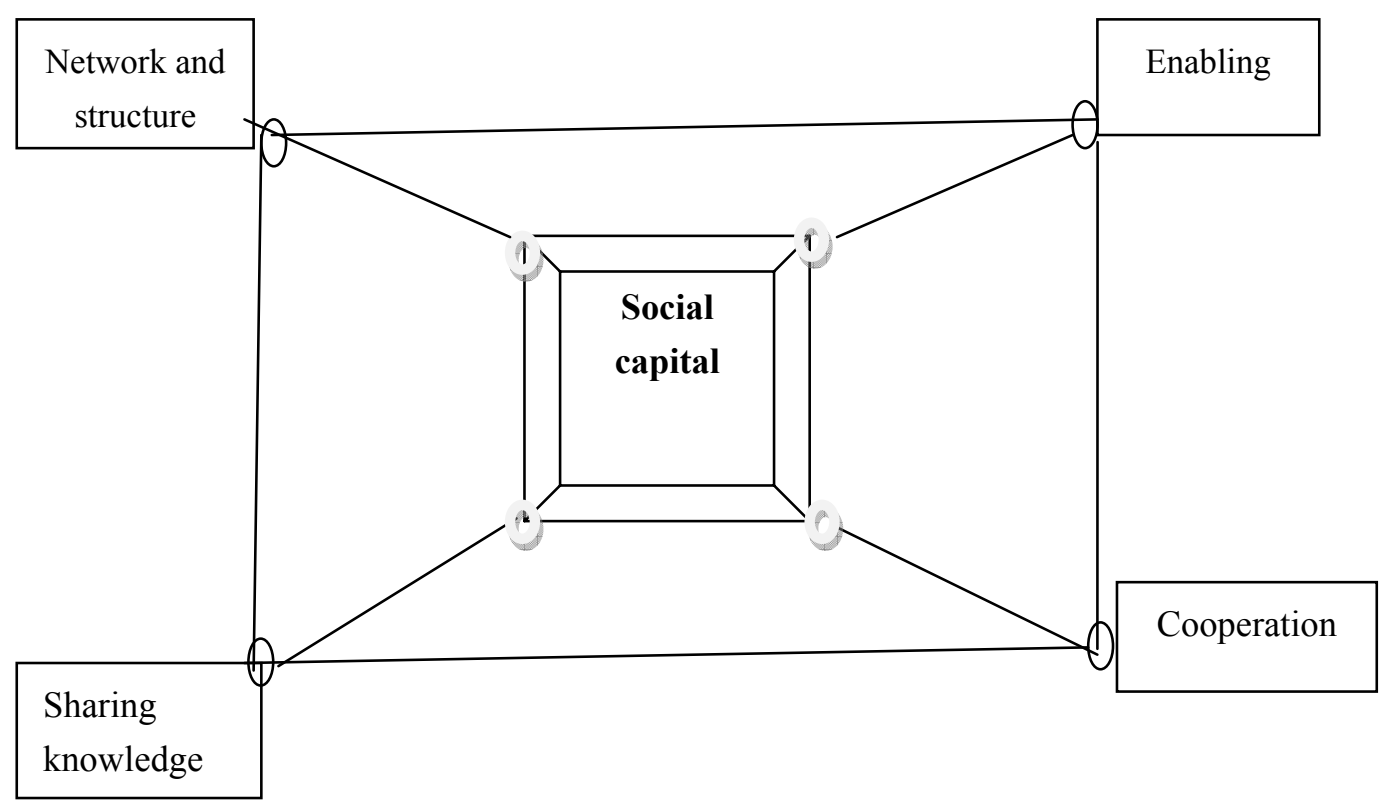

Figure 1. The conceptual research model

Available status

Appropriate status

\section{Research Methodology}

Whereas research finding is mixed of explorative findings, researcher attempts to find suitable grounds. In this way, the qualitative data (describing endless aspect of phenomenon) is collected. Then by initial recognition, the ability of classifying questions about phenomenon is offered. In the next stage, researcher may test research questions through collecting quantitative data (Bazargan, 2008). This research with respect to objective is applied and with respect to method of collecting descriptive information is correlation and survey. On this basis, by using qualitative attitude the aspects, components and indices of social capital is recognized and the elementary research model is designed. In next stage, according to the obtained information from previous stage, the aforesaid model from Islamic Azad University Zahedan Branch (as case study) is evaluated (quantitative 
approach). The sampling method is simple random method and in order to determine volume sample it was benefit from Korjesi and Morgan decision making model (Omaskaran, 2002). The methods of collecting information are including: library study (books, journals, database, Internet ...) questionnaire by using SPSS software the amount of trust coefficient is calculated with Alpha Cronbach and the statistical society of this research is professors of Islamic Azad University, Zahedan Branch. In order to study causative relationship between variables it was benefit from structural equations with multi variable analysis including: Confirmatory Factor Analysis, Classical Simultaneous Equation Models, Path Analysis, multi regression, variance analysis and other statistical methods.

\section{Research Hypothesis (Principal Hypothesis and Subsidiary Hypothesis)}

There is significant difference between available status and appropriate status of social capital in statistical society (principal hypothesis).

According to the results obtained from $4^{\text {th }}$ table it is found out that there is gap between social capital about available status and appropriate status. According to results of table by having $95 \%$ average, the social capital is not within available status and appropriate status. Therefore, by $95 \%$ certainty it is possible to reject zero hypothesis and the hypothesis of researcher is approved. Results of research hypothesis are compatible with results of research of Gamas (2007) and research of Ahanchian (2005). Therefore, according to results of this hypothesis (gap between available status and appropriate status) the following recommendations are offered for filling the gap between available status and appropriate status at universities:

$\checkmark$ Preparing working environment for employees on partnership and teamwork basis for solving deficiencies;

$\checkmark \quad$ Priority of public interest to personal interest;

$\checkmark$ Attention to individual and social aspects of work environment;

$\checkmark$ Benefiting from skilful and qualified managers and employees for increasing efficiency of organization;

$\checkmark$ Benefiting from managers in workspace based on trust that delegate responsibility to their inferior persons according to this item;

$\checkmark$ Benefiting from employees having clear identity that their qualification and loyalty to organization is proved;

$\checkmark \quad$ Benefiting from persons having team working morale.

There is significant difference between available status and appropriate status of social capital in statistical society (subsidiary hypothesis).

Table 1. Statistical indices for studying social capital in available status

\begin{tabular}{llll}
\hline Average & Standard Deviation & $\begin{array}{l}\text { Estimating Average Distance of Social Capital in Available Status with Certainty Level of } \\
\mathbf{9 5 \%}\end{array}$ \\
\hline & & Low limit of certainty & High limit of certainty \\
2.55 & 0.52 & -0.50 & -0.38 \\
\hline
\end{tabular}

According to the results of research from tables, it is concluded that according to enabling aspect of social capital there is no gap between available status and appropriate status; therefore, by $95 \%$ certainty it is possible to state that the hypothesis of researcher is rejected and the zero hypothesis is approved. Results of research hypothesis is compatible with results of research by Gamas (2007) and research by Feizi (2006).

There is significant difference for aspect of cooperation and public interest between available status and appropriate status of social capital in statistical society (subsidiary hypothesis).

Table 2. Results of T-student test

\begin{tabular}{lllll}
\hline Calculated T & Degree of Freedom & Sig Level & Error Level & Result of Test \\
\hline-13.75 & 265 & 0.000 & 0.05 & Rejecting H0 \\
\hline
\end{tabular}


Table 3. Statistical indices of studying social capital in appropriate status

\begin{tabular}{llll}
\hline Average & Standard Deviation & $\begin{array}{l}\text { Estimating Average Distance of Social Capital in Available Status with Certainty Level of } \\
\mathbf{9 5 \%}\end{array}$ \\
\hline & Low limit of certainty & High limit of certainty \\
3.83 & 0.69 & 0.74 & 0.91 \\
\hline
\end{tabular}

Table 4. Results of T student test

\begin{tabular}{lllll}
\hline Calculated T & Degree of Freedom & Sig Level & Error Level & Result of Test \\
\hline 19.50 & 265 & 0.000 & 0.01 & Rejecting H0 \\
\hline
\end{tabular}

Table 5. Average ranks of freedman test in order to study 4 aspects of consisting social capital in available status

\begin{tabular}{llllll}
\hline Row & Variable & Average Rank & Priority & Degree of Freedom & Sig \\
\hline 1 & Identity & 5.07 & Identity & 6 & 0.000 \\
2 & Enabling & 3.59 & Trust & & \\
3 & Sharing knowledge & 4.36 & Cooperation and public interest & \\
4 & Social and structural network & 3.21 & Social and structural network & \\
\hline
\end{tabular}

Table 6. Average ranks in Freedman test in order to study 7 aspects consisting of social capital in appropriate status

\begin{tabular}{|c|c|c|c|c|c|}
\hline Row & Variable & Average Rank & Priority & Degree of Freedom & Sig \\
\hline 1 & Enabling & 4.18 & Trust & & \\
\hline 2 & Cooperation and public interest & 3.24 & Enabling & & \\
\hline 3 & Sharing knowledge & 4.66 & Cooperation and public interest & & \\
\hline 4 & Social and structural network & 3.67 & Social and structural network & & \\
\hline
\end{tabular}

Table 7. Sig Freedman test

\begin{tabular}{ll}
\hline Calculated Amounts & Statistical Indices \\
\hline 266 & No \\
86.979 & $\chi$ \\
6 & Degree of Freedom \\
0.000 & Sig \\
\hline
\end{tabular}

According to the results of research from $4^{\text {th }}$ chapter, it is concluded that according to cooperation and public interest aspect of social capital there is no gap between available status and appropriate status; therefore, by $95 \%$ certainty it is possible to state that the hypothesis of researcher is rejected and the zero hypothesis is approved. Results of research hypothesis are compatible with results of research by Totarman and Wolf (2006) and research of Ahanchian (2005).

There is significant difference aspect of sharing knowledge between available status and appropriate status of social capital in statistical society (subsidiary hypothesis).

According to the results of research from $4^{\text {th }}$ chapter, it is concluded that according to sharing knowledge aspect of social capital there is no gap between available status and appropriate status; therefore, by $95 \%$ certainty it is possible to state that the hypothesis of researcher is rejected and the zero hypothesis is approved. Results of research hypothesis are compatible with results of research by Totarman and Wolf (2006) and research of Feizi (2006).

There is significant difference aspect of social and structural network between available status and appropriate status of social capital in statistical society (subsidiary hypothesis).

According to the results of research from $4^{\text {th }}$ chapter, it is concluded that according to social and structural 
network aspect of social capital there is no gap between available status and appropriate status; therefore, by $95 \%$ certainty it is possible to state that the hypothesis of researcher is rejected and the zero hypothesis is approved. Results of research hypothesis are compatible with results of research by Hari Wanbori (1999) and research of Feizi (2006).

Comparative study of available status and appropriate status of social capital at universities (recognizing gap between available status and appropriate status and offering recommendations for filling the gap between 2 statuses:

Comparing between aspects (identity, enabling, cooperation and public interest, trust, partnership management, sharing knowledge, social and structural networks) consisting of social capital within available status and appropriate status has gap with respect to 7 aspects including (identity, partnership management, sharing knowledge, social and structural networks) there is gap between available status and appropriate status and for aspect of (enabling, cooperation, public interest and trust) there is no gap between available status and appropriate status i.e. whereas comparing averages of these 2 hypothesis and with respect to available status and appropriate status, it is concluded that since social capital at available status is 3.38 and the average social capital at available status is 2.55 ; therefore, level of social capital at available status until reaching to appropriate status have gap that should be filled or reduced with the following recommendations:

$\checkmark$ Planning for obtaining to common values of managers and employees for reaching to common and pre-determined goals;

$\checkmark$ Benefiting from skilful and qualified human workforce;

$\checkmark$ Assessment of current performance of employees each 3 months and comparing it appropriate status and offering model for eliminating problems of available status and appropriate status;

$\checkmark$ Benefiting from managers making decision on partnership basis and skilful counselors;

$\checkmark$ Increasing friendly relationship between managers and employees;

$\checkmark$ Attention to all aspects of social capital at workspace;

$\checkmark$ Benefiting from managers and employees that are familiar with these 7 items;

$\checkmark$ Preparing friendly workspace for increasing efficiency of organization;

$\checkmark$ Encouraging managers and employees to attend at enabling, trust, identity and partnership management course;

$\checkmark$ Assessment for performance of managers and employees for filling the gap between available status and appropriate status;

$\checkmark$ Preparing environment for managers and employees to become more familiar with this term and general concept.

\section{Discussion \& Result Analysis}

As it was expected, social capital and organizational readiness for establishment of knowledge management has positive relationship and having such relationship is logical. In fact, social capital is necessary for developing and distributing knowledge in organization. From organizational point of view, social capital is regarded as potential and actual resource that is defined as accessible means through network of relationship for a person or a social unit. Finally the importance of organizational social capital is due to society of people (groups, teams) that may successfully complete tasks and create feeling of mutual trust and cooperation. IT factor covers all aspects of communication that consists of hardware and software and being accessible. Whereas humanities topic is regarded for each change, it is benefit for improving methods at central groups of knowledge management and offering guidelines and increasing communication of system and distributing knowledge. In fact, having high level of social capital with facilitating communication may reduce this time.

Solutions:

According to role and application of social capital in society, it is expected to establish required support framework for executing social capital in universities on behalf of government. This research shows that social capital in university from structural and applied point of view is at elementary level. In this level a set of recommendations are separately offered for each of then 7 aspects of social capital and also increasing application of social capital in universities for governmental authorities, persons in charge, managers and employees including:

Therefore it is recommended to improve cooperation and public interest of social capital to take following activities (there is no gap between available status and appropriate status of social capital with respect to this aspect) 
1) Encouraging governmental authorities, managers and administrative employees to continue the mutual communication for preparing healthy and friendly atmosphere at workspace and organization that lead to organizational growth and development;

2) Acknowledgment of employees that concept of social capital has application in their workspace;

3) Creating organizational obligation through applying justice for distributing bonus and development opportunities, effective and fair feedback about job application and partnership of people in strategies and programs of company;

Therefore, it is recommended to improve trust aspect at social capital to take following activities (there is no gap between available status and appropriate status of social capital with respect to this aspect).

1) Planning for domestic communication about inner personal communication, communication between organizational units, creation of mutual trust based communication between managers and employees;

2) Holding courses for extending concepts of social capital on seminar and conference;

3) Cooperation and media assistance (national media) for correct transfer of social capital concept.

Therefore, it is recommended to improve social and structural network aspect at social capital to take following activities (there is gap between available status and appropriate status of social capital with respect to this aspect)

1) Creating team, increasing feeling of organizational identity at company for regarding employees and managers of organization as member of a common family;

2) Benefiting from service compensation system that offers bonus for teamwork and group work and applying from policies of human resource and offering effective service for developing broad network of relationship based on trust;

3) Applying recruitment procedures that not only to regard specialty but also to consider social personality i.e. ability of person for communicating with others and being interested in team work.

\section{Recommendations for Further Research}

Result of this research is basics for beginning further research in the field of social capital among universities. In this research it is determined that universities are not mature in the field of social capital; therefore, it is required to perform more research in this relation and to recognize its reasons and challenges. Thus, the following recommendations are offered:

- To carry out research in relation to increasing interest and executing indices of social capital;

- To carry out research in relation to developing social capital between managers and employees;

- To carry out research in relation to each of the components of social capital by comparative research;

- To carry out research in relation to social capital and its application for all organizations specially education;

- To carry out research in relation to social capital and direct influence on increasing efficiency;

- To carry out research in relation to social capital and factors preventing from its execution;

- To carry out research in relation to different type of social capital and comparative study;

- To carry out research in relation to executing social capital among different organizations;

- To carry out research in relation to mind of people (managers and employees) and their point of view toward social capital;

- To carry out research in relation to enthusiasm of people for learning social capital;

- To carry out research in relation to influence of social capital on organizational structure;

- To carry out research in relation to relationship between social capital and human capital.

\section{References}

Abdullahi \& Mousavi. (1385). Social capital in Iran and existing industry, future outlook and possible origin of the transition. Journal of Social Welfare, 25.

Ahanchian, N. (1384). Academic leadership and social capital, sociology approach to higher education management. Modern Educational Thought, 2(3\&4).

Alvani, M., \& Syed Naqvi, M. A. (nd.). Social capital: Concepts and Theories. Journal of Management Studies, 33(34), 3-13. 
Astigitz, J. (1385). Globalization and its problems, translating by Golriz. Tehran, Ney publication printing 1.

Baker, W. (1382). Management and social capital. Tehran: Industrial Management.

Campano, F., \& Salvatore, D. (2011). Economic Development, Income Distribution and the Kuxnets Hypothesis. Journal of Policy Mokeline, 10.

Coleman, J. (1377). Foundations of Social Theory (1st ed.). Tehran, Ney Publication.

Feizi, T. (1385). Designing and explaining the social capital model. Payam Noor university Ph.D. thesis, Public Administration, University of Allameh Tabatabai

Gallagher, D., Ting, L., \& Palmer, A. (2008). A Journey into the Unknown: Taking the Fear out of Structural Equation Modeling with AMOS for the First-Timer User. The Marketing Review, 255-275

Hair, J. F., Black, W. C., Babin, B. J., Anderson, R. E., \& Tatham, R. (2006). Multivariate Analysis (6th ed.). New Jersey: Pearson Education Inc.

Jha, S. K. (2009). Fiscal Policy, Income Distribution, and Growth. Asian Development Bank Economic and Development Resource Center (EDRC). Report Series No.

Juhetch, M. (1385). Organization Theory (2nd ed.). Tehran: Afkar publishing.

Kumar, V., Smart, P. A., Maddern, H., \& Maull, R. S. (2008). Alternative Perspectives on Service Quality and Customer Satisfaction: the Role of BPM. International Journal of Service Industry Management.

Kuznets, S. (2008). Econimic Growth and Income Ineguality. American Ecanomic Review.

Papanek, G., \& Kyn, O. (2012). The Effect on Income Distribution of Development, The Growth Rate and Economic Strategy, Jornal of Development Economics, 23.

Ram, R. (2006). Economic Development and Income Inequality: Further Evidence on the U Curve Hypothesis. World Development, 16(11).

Shareh, P. M. (nd). Social capital: Conceptualization, measurement and policy implications, Management and Planning Organization of Mazandaran province. Iran.

\section{Copyrights}

Copyright for this article is retained by the author(s), with first publication rights granted to the journal.

This is an open-access article distributed under the terms and conditions of the Creative Commons Attribution license (http://creativecommons.org/licenses/by/3.0/). 